\title{
JOGOS TEATRAIS COMO MEDIADORES DO DIÁLOGO ENTRE EDUCAÇÃO E COTIDIANO SOCIAL: APONTAMENTOS TEÓRICO- METODOLÓGICOS
}

\author{
THE CONTRIBUTIONS OF THEATRICAL GAMES FOR DIALOGUE \\ BETWEEN EDUCATION AND SOCIAL EVERYDAY: NOTES \\ THEORETICAL-METHODOLOGICAL
}

DOI: http://dx.doi.org/10.5965/1984317813022017054

Marcos Antonio Ferreira dos Santos, Mary Anne Vieira Silva - UEG/TECCER

\begin{abstract}
RESUMO
O texto é constituído por reflexões teóricas sobre os jogos teatrais como possibilidades formativas do sujeito social. Os jogos são dispositivos de ensino que contemplam os propósitos dos Parâmetros Curriculares Nacionais visando uma aprendizagem construtivista. Dentre os objetivos destacamos: apresentar os jogos teatrais como propostas educativas críticas dos contextos sociais cotidianos; abordar os pressupostos educacionais para o ensino de arte/teatro; discutir sobre o teatro como linguagem educacional. Ademais, a análise circunscreve a teoria dos jogos teatrais a partir do campo da percepção focalizando as mediações perceptivas, imaginativas e dramáticas para a formação do sujeito crítico. Metodologicamente, o estudo realiza-se por uma revisão bibliográfica teórica e conceitual. Dentre os resultados, expomos que os jogos teatrais se apresentam em uma relação dialética em que o exercício do teatro permite ao educando por meio do próprio teatro e de seus instrumentos de ensino melhores rendimentos escolares, além de aguçar percepções sobre a realidade cotidiana, contribuindo para o incremento de um ser humano crítico.
\end{abstract}

Palavras-chave: Jogo. Teatro-educação. Linguagem.

\begin{abstract}
The present text consists in theoretical reflections about theater games seen as formative possibilities of the social subject. The games are teaching devices in accordance with the purposes of the National Curricular Parameters, aiming for a constructivist learning. Among our goals, we highlight: To present the theater games as educational proposals which are critical of the everyday social contexts; To approach the educational presuppositions of the teaching of art/theater; To discuss the theater as an educational language. Moreover, the analysis circumscribes the theory of theater games to the field of perception, focusing the perceptive, imaginative e dramatic mediations to the formation of the critical subject. Methodologically speaking, the study is made by a bibliographical, theoretical and conceptual. Among the results, we show that the theater games present themselves in a dialectical relation wherein the practice of the theater allows the student, by means of the own theater and its teaching devices, to have better school results, in addition to sharpening perception of the everyday reality, contributing to the improvement of a more critical human being.
\end{abstract}

Keyword: Game. Theater-education. Language. 


\section{INTRODUÇÃO}

O texto permite construir um diálogo, entre os saberes práticos no teatro com as leituras e práticas acadêmicas, no sentido de contribuir e promover reflexões sobre as metodologias teatrais na prática educativa escolar. Partimos do pressuposto que a aproximação do educando com o teatro decorre da valorização dos elementos do cotidiano social, sobretudo aqueles que se apresentam como constitutivos da formação crítica do sujeito social.

A amálgama do teatro com o cotidiano pode se tornar possível quando inserida em uma prática escolar, por meio da aplicação dos jogos teatrais, principalmente quando esses assumem o papel de estabelecer um caminho para análise do contexto social do discente. Essa inter-relação ocorre em uma situação, em que se procura entender as formas pelas quais os sujeitos sociais estruturam suas aprendizagens sobre o mundo e como esses determinam suas ações. Os jogos teatrais, nesse artigo, são analisados no contexto de encenações teatrais na escola contribuindo para a criação de personagens, elaboração e criação colaborativas de um texto ou uma encenação teatral, em que o lúdico é o meio dinamizador de atividades educativas criadoras.

Os jogos teatrais são possibilidades criadoras de promover diversas percepções sobre o cotidiano social. Dentre essas percepções destacamos aquelas voltadas para as realidades cotidianas que reforçam os quadros das desigualdades sociais como: violência, racismo, preconceito, sexualidade, afetividade e outros. Concordamos que o jogo teatral, em sala de aula, favorece para a construção crítica do contexto sociocultural, diretamente, conexo às possíveis representações acerca da realidade vivida pelos próprios educandos. O jogo teatral permite apresentar e analisar questões importantes e fundamentais sobre a realidade social do aprendiz.

De acordo com Koudela (1990) existem várias categorias de jogos, a saber: sensoriais, dramáticos, intelectuais, de regras, de observação e muitos outros. Como ferramenta de ensino, cabe ao professor escolher o jogo oportuno que possa solucionar problema e colaborar para os enfrentamentos que o educando terá diante da realidade social. Os jogos teatrais e sua aplicabilidade no cotidiano escolar são abordados nas reflexões fenomenológicas de Merleau- 
Ponty. O marco teórico se ancora na percepção e no campo existencial do sujeito social, por meio do uso dos jogos dramáticos e teatrais como prática inventiva educacional.

\section{JOGOS TEATRAIS E SUAS CONTRIBUIÇÕES PARA UMA PRÁTICA EDUCATIVA: NA TRILHA CRÍTICA DOS CONTEXTOS SOCIAIS COTIDIANOS}

Os jogos teatrais como campo investigativo se centram no contexto educacional contemporâneo, em que atualmente torna-se necessário uma mudança epistemológica para o tratamento dos conhecimentos aplicados à área de arte. É mister, destacar que essa mudança no eixo interpretativo, sobre como atuar em contextos artísticos no ensino básico regular, prima por um tratamento em que as questões sociais, culturais, econômicas e políticas devem ser tratadas por uma abordagem crítica. Essa deve conduzir o educando a pensar sobre novas atitudes que proporcionem determinadas mudanças interpretativas de contextos sociais que se apresentam tão díspares e desiguais à percepção de mundo do educando.

Essa mudança interpretativa remete para o exercício de práticas educacionais, diretamente, concernentes às proposições contidas nos Parâmetros Curriculares Nacionais e na Lei de Diretrizes e Bases da Educação Brasileira, lei no 9394/96. Tais dispositivos legais impõem aos licenciados em arte e docentes, a árdua reformulação crítica dos instrumentos operacionais de ensino.

Nesse contexto, os jogos teatrais se apresentam como possibilidades de prática educativa e como instrumento metodológico que mediam a construção da arte dramática frente aos imputados contextos sociais vivenciados cotidianamente, a exemplo de temas como sexualidades, afetividades, violências dentre outros.

Ainda, para um esforço explicativo, sobre o entendimento dos jogos teatrais e da prática educacional é importante ressaltar que os teóricos formuladores dos parâmetros curriculares reforçam sobre a concepção de que os conhecimentos de arte devem ter como objetivos centrais: o desenvolvimento de senso crítico, a capacitação dos educandos por meio de formas interpretativas do mundo, nas quais o uso de linguagens múltiplas possa ser empregado cotidianamente. A esse respeito destacamos a seguinte proposição contida nos Parâmetros Curriculares Nacionais, 


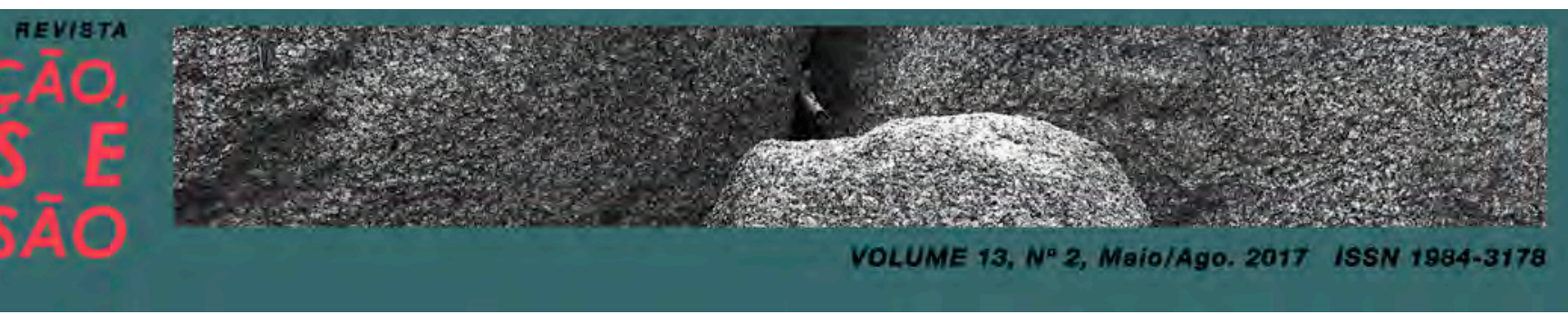

[...] utilizar as diferentes linguagens - verbal, musical, matemática, gráfica, plástica e corporal - como meio para produzir, expressar e comunicar suas ideias, interpretar e usufruir das produções culturais, em contextos públicos e privados, atendendo a diferentes intenções e situações de comunicação [...] (BRASIL, 1998, p. 68).

O jogo teatral para o presente estudo é uma atividade prática que promove uma fecunda proposta educativa capaz de contribuir com que o educando, realize seu processo de aprendizagem formal a partir de conteúdos artísticos/teatrais e que garanta uma formação deste ser humano social e livre, intercedida pelo pensamento crítico e pelas experiências vividas em grupo.

Sabe-se que nas propostas pedagógicas para o ensino de arte, o teatro se apresenta como uma linguagem múltipla, mas se reconhece que o exercício teatral promove movimentos de mudanças de várias ordens no indivíduo, seja no comportamental (desinibição) e intelectual (rendimento escolar). A experiência do teatro revela que a criação e improvisação estão no cerne da atividade do jogo teatral, feito que, consideramos fundamental para o exercício de uma atividade mais reflexiva e com ganho de consciência crítica dos sujeitos sociais que participam dos jogos teatrais. Os sujeitos passam a partilhar do entendimento de que,

[...] o teatro, enquanto proposta de educação, trabalha com o potencial que todas as pessoas possuem, transformando esse recurso natural em um processo consciente de expressão e comunicação. A representação ativa integra processos individuais, possibilitando a ampliação do conhecimento da realidade. (KOUDELA, 1990, p. 78)

Ainda nessa visão de que o teatro se traduz por uma linguagem formativa é possível afirmar que esse produz no indivíduo campos críticos sobre a existência e atuação do sujeito no mundo. Acrescentamos nessa visão que o jogo teatral pode se tornar uma ferramenta educativa de construção da identidade e autonomia, características de um sujeito emancipado.

No jogo teatral "as regras estão alicerçadas em um momento para a avaliação das representações de cada um, ou de cada grupo, colocando nos jogadores a responsabilidade de discutir e dialogar sobre o que foi feito, sem buscar a resposta certa", (SPOLIN, 2001, p.18). 
De acordo com a autora, essa resposta de fato não existe, pois não existe apenas uma forma de representar.

Para atender o propósito de correlacionar os jogos teatrais como uma forma de linguagem educativa, ainda destacamos que eles também atendem aos propósitos de que os educadores devem fazer uso de ferramentas de ensino a fim de,

[...] saber utilizar diferentes fontes de informação e recursos tecnológicos para adquirir e construir conhecimentos; questionar a realidade formulandose problemas e tratando de resolvê-los, utilizando para isso o pensamento lógico, a criatividade, a intuição, a capacidade de análise crítica, selecionando procedimentos e verificando sua adequação [...] (BRASIL, 1998, p. 73).

Nesse sentido, os jogos teatrais e ou dramáticos se apresentam como formas interpretativas do cotidiano. De acordo com Oliveira (2007), os jogos teatrais estão inseridos em todo o contexto da existência humana e ainda demarcam campos funcionais que atuam em duas básicas concepções: as lúdicas e as educativas. Essas concepções para o campo educacional compreendem as seguintes definições: Função lúdica — o jogo proporciona a diversão, o prazer e até o desprazer quando escolhido voluntariamente; Função educativa o jogo ensina qualquer coisa que complete o indivíduo em seu saber, seus conhecimentos e sua apreensão do mundo.

Diante dessas concepções, afirma-se a correlação do jogo teatral com a ideia de prática educativa. Como o teatro promove o desvelamento crítico das questões sociais? Como o jogo teatral pode contribuir para a formação do indivíduo social e produtor de conhecimentos críticos, a partir de uma prática coletiva numa perspectiva educativa? Como promover à práxis consciente entre o exercício da arte e a formação escolar? Tais inferências centram-se diretamente nos constructos ideológicos contidos nos Parâmetros Curriculares Nacionais, quando esses apontam que,

O aluno desenvolve sua cultura de arte fazendo, conhecendo e apreciando produções artísticas, que são ações que integram o perceber, o pensar, o aprender, o recordar, o imaginar, o sentir, o expressar, o comunicar. A realização de trabalhos pessoais, assim como a apreciação de seus trabalhos, 


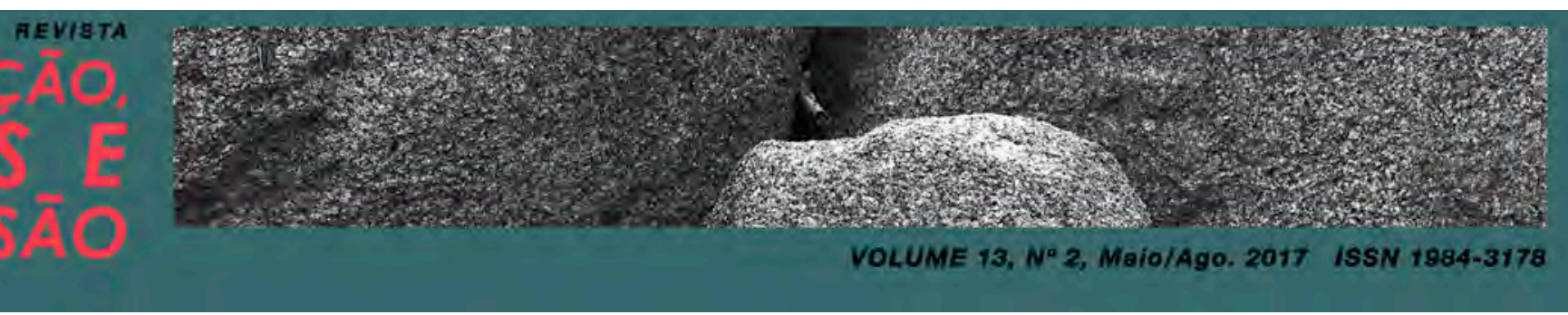

os dos colegas e a produção de artistas, se dá mediante a elaboração de ideias, sensações, hipóteses e esquemas pessoais que o aluno vai estruturando e transformando, ao interagir com os diversos conteúdos de arte manifestados nesse processo dialógico (BRASIL, 1998, p. 74).

Diante do enunciado, a práxis consciente decorre desse processo dialógico, que se funda em um contexto dialético. Para esse entendimento depreendemos da opinião de que o teatro se apresenta como arena de produção e assimilação de conteúdos que se transformam e se metamorfoseiam de forma cambiante entre a arte de interpretar (atuar/encenar) e a prática de assimilar (apreender/memorizar).

Diante dessa relação dialética promovida pelo exercício do teatro, o educando por meio do próprio teatro e de seus instrumentos de ensino pode garantir um maior rendimento escolar de questões que aparentemente se colocam com determinadas complexidades, em termos de assimilação, como por exemplo, posicionamento de como enfrentar as questões que evocam as desigualdades sociais, as demarcações identitárias (sexual, religiosa, gênero e outras) e os reconhecimentos de contextos análogos as suas vivências (violência, pobreza, discriminação).

Nesse sentido, o teatro pode facilitar a formação crítica de mundo, em que o educando como espectador ou ator ganhará múltiplas percepções de uma dada realidade. Para tanto, o jogo teatral permite várias interfaces com a prática educativa escolar.

\section{O JOGO TEATRAL E OS PRESSUPOSTOS EDUCACIONAIS PARA O ENSINO DE TEATRO}

Os postulados que garantem formular as interações entre o jogo teatral e as práticas educacionais são balizados nas concepções de Oliveira (2007), a partir dos estudos de Japiassu (2007), Spolin (2001a) e Desgranges (2006). Reconhecemos que o jogo promove "crescimento pessoal e o desenvolvimento cultural dos jogadores", (JAPIASSU, 2007, p.20).

Nessa perspectiva o autor supracitado expõe que o jogo teatral se apresenta como uma prática de ganho individual que modifica determinados comportamentos pessoais. De acordo com essa ideia é possível compreender que a prática do jogo teatral permite mudanças sempre 


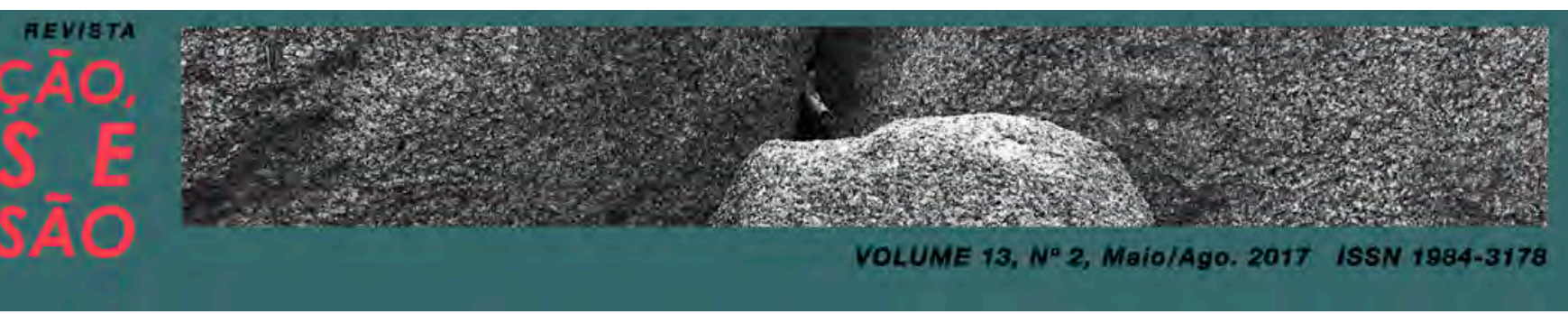

submetidas a determinados contextos, sejam eles ambientais, culturais e ou psicológicos. Essa visão recoloca o jogo teatral frente ao entendimento de que ele se realiza garantindo o aperfeiçoamento em uma instância individual.

Outra contribuição advém da concepção de que "o jogo além de ser uma atividade comum realizada em grupo, proporciona o envolvimento e a liberdade individual, fatores importantes para o desenvolvimento da experiência”, (SPOLIN, 2001, p.5). Essa visão acrescenta o aspecto primordial da experiência como uma prática cultural.

A concepção acima propalada permite a compreensão de que o jogo teatral se apresenta como mediação prática do campo experencial, esse campo é apreendido por meio das sensibilidades individuais e das reconstruções coletivas. O jogo é um exercício de enfrentamento e de reconstrução dos constructos históricos em todos os âmbitos que conformam o cotidiano das pessoas.

Ainda destacamos por meio da revisão dos postulados anunciados, que o jogo "desenvolve a possibilidade de elaborar maneiras particulares de compreender o mundo, os acontecimentos cotidianos, tanto no que concerne à vida pessoal, quanto no que se refere às questões sociais coletivas", (DESGRANGES, 2006, p.89).

Essa última concepção, abre a possibilidade de se compreender o instrumento do jogo teatral como uma forma que organiza os sentidos da vida, tornando-se uma via fecunda para a formação de um complexo campo perceptivo. O jogo ainda constitue-se como forma estrutural que se efetiva por processos diretos e indiretos da imaginação que se revelam pela e na capacidade de criar, conceber situações, fatos, concepções e sensibilidades que se fazem por meio da articulação de múltiplas linguagens.

Os jogos teatrais são dinâmicas lúdicas e educacionais, e acionam os princípios de reconhecimento das diferenças e da alteridade frente as estruturas sociais configuradas na sociedade brasileira contemporânea, segundo Oliveira (2007).

A prática teatral envolve inúmeros gêneros artísticos e múltiplos caminhos que se abrem como possibilidades efetivas de conhecimentos educativos. Inicialmente fazer teatro, numa visão reduzida, seria a arte de interpretar. A interpretação passa diretamente por estruturas ligadas aos campos artisticos que requerem aptidões de imaginação e de criação de 
contextos, de cenários e de personagens. Para essa discussão nos apoiaremos no que concerne à finalidade do teatro didático.

O teatro didático se define por,

todo teatro que visa instruir seu público, convidando-o a refletir sobre um problema, a entender uma situação ou adotar uma certa atitude moral ou política. Na medida em que o teatro geralmente não apresenta uma ação gratuita e privada de sentido, um elemento de didatismo acompanha necessariamente todo trabalho teatral. O que varia é a clareza e a força da mensagem, o desejo de mudar o público e de subordinar a arte a um desígnio ético ou ideológico. O teatro didático stricto sensu é constituído por um teatro moralizador (as moralidades* no final da Idade Média) ou político (o agit-prop ou os Lehrstucke brechtianos). [...] Foram feitas inúmeras experiências no século XIX, na Europa, ou hoje, no Terceiro Mundo, para fazer com que um público desfavorecido (de operários, de camponeses, mas também de crianças que, muitas vezes, nao têm direito a uma forma de expressão específica) conheça uma arte muitas vezes difícil e cuja contribuição para uma transformação social é esperada por artistas e intelectuais (PAVIS, 2008, p. 386).

O teatro então, em uma abordagem didática promove ao público a interação de ações lúdicas interrelacionadas com as ações que perpassam por um exercício social e de cunho crítico. Tal abordagem promove pensar o teatro como uma prática de valores educativos. $\mathrm{Na}$ esteira da ação social o teatro promove, ainda, a ideia de compreensão mútua da solidariedade e do respeito em convivência social coletiva.

Para Koudela (1990), a proposta de se fazer teatro em uma abordagem educativa acontece a partir das fases interpretativas da concepção do Teatro- Educação ao longo da história. A autora destaca em seu livro Jogos teatrais, que o campo que demarca o TeatroEducação permeia as concepções "contextualistas”, sobretudo aquelas ligadas as necessidades psicológicas e as concepções "essencialistas" sendo essas ligadas as contribuiçoes do teatro para os campos da experiência humana.

O sujeito social que nesse estudo é o educando por meio do teatro potencializa e desenvolve seus processos cognitivos de aprendizagens ligados as experiências individuais e coletivas. No que se refere às fases do Teatro-Educação, ressalta que numa perspectiva tradicional o teatro "tinha apenas a função de preparar o espetáculo, não cuidando de formar o 
indivíduo", (KOUDELA, 1990, p. 18). Concepção que se transforma a partir do movimento que revoluciona o ensino de teatro na escola, denominado Escola $\mathrm{Nova}^{1}$, que não faz referência a um único sistema didático ou a um estabelecido tipo de escola. Outra fase destacada pela a autora está relacionada à visão da educação progressista centrada no desenvolvimento do educando a uma instância natural, ficando a cargo do professor a função de guiar o aluno. O que se tinha de progressivo para a arte do teatro nessa perspectiva era que, o guia/professor, promoveria no educando a liberdade de criação. A contribuição dessa visão progressiva, no contexto da Escola Nova para a educação promoveu ao ensino de arte a inserção de vários conteúdos artísticos nos curriculos educacionais brasileiros.

De acordo com o estudo de Koudela, o ensino de Teatro-Educação vivencia nas últimas décadas a dicotomia entre teatro e manifestação espontânea. Conforme aponta a autora "quando o teatro é citado, ele é concebido de forma abstrata ou através da negação de modelos tradicionais, substituídos em nome do conceito genérico de criatividade" (KOUDELA, 1990, p. 22). A literatura do teatro aponta que as mudanças ocorridas tanto na filosofia, quanto na psicologia educacionais, influenciaram nas abordagens criativas do teatro, sobretudo aquelas voltadas para a valorização das experiências humanas. Tais mudanças geram para o contexto do Teatro-Educação a inclusão de novas abordagens que valorizam os comportamentos, a partir de objetivos educacionais.

É nesse contexto que os jogos teatrais emergem como dispositivos de práticas educativas, que proporcionam desenvolvimento pessoal e coletivo. Ainda baseando-se em Koudela (1990), o sentido da criatividade, a partir dos jogos, deve garantir esses desenvolvimentos, considerando os seguintes aspectos,

Experiência em pensar criativo e independentemente. Imaginação, iniciativa desenvolvem-se rapidamente na atmosfera criada pelo professor; Prática de cooperação social; Desenvolvimento da sensibilidade para relacionamentos pessoais e uma profunda simpatia humana, através da analise e do desempenho de várias personagens em situações diversas; Liberação emocional controlada; Experiências de pensamento independente, expressando ideias claras e efetivamente. $\mathrm{O}$ resultado de uma experiência

\footnotetext{
${ }^{1}$ A Escola Nova foi um movimento de renovação do ensino que foi especialmente forte na Europa, na América e no Brasil, na primeira metade do século XX. O escolanovismo desenvolveu-se no Brasil sob importantes impactos de transformações econômicas, políticas e sociais. (HAMZE, Amélia. Escola Nova e o movimento de renovação do ensino. Em: http://educador.brasilescola.com/gestao-educacional/escola-nova.htm. Acessado em: 03/07/2013).
} 


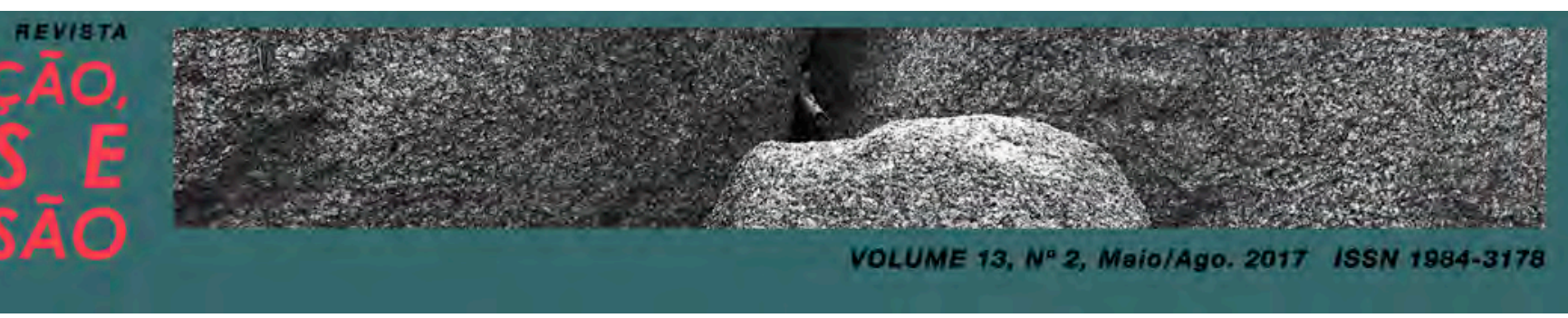

como essa em improvisações é uma conquista de flexibilidade de corpo e voz. (SPOLIN, 2001, p.146)

Os referidos aspectos promovem reflexões para o uso dos jogos teatrais a partir de abordagens que promovem o conhecimento do ser e do mundo através de uma prática de trabalho em equipe, de forma cooperativa a fim de desenvolver a autoestima dos indivíduos. Além de promover um crescimento pessoal capaz de ser expresso criativamente através de um projeto comum. Isto inclui dizer que a arte do teatro, por meio dos jogos teatrais possibilitam aprender a ser, não apenas para ser, mas um ser criativo e crítico de sua própria concepção de mundo.

Consideramos então, o teatro como uma forma de jogo, uma vez que, a raiz do teatro está no jogo. O teatro, em sua essência, é uma espécie de jogo, que consiste em parar o tempo e recriar situações de um espaço mágico. O teatro como jogo oferece o conhecimento por meio da emoção. O jogo dramático é também um meio de liberar agressão e conflitos. Isto é, um instrumento para o conhecimento de uma realidade múltipla e complexa, por sua vez, é um meio para o autoconhecimento por um processo crítico/reflexivo.

Os jogos dramáticos promovem experiências que conduzem a quebra de estereótipos, além de incentivarem a sensibilidade, o sentido crítico, a solidariedade, o respeito, a empatia e a consciência social. O teatro traz em si, a concepção de despertar naqueles envolvidos, a imaginação, a fantasia e o pensamento criativo. O teatro é uma arte em sua dimensão humana. Ainda promove a interelação entre o sujeito e objeto da arte que é o ser, em si mesmo. Com sua linguagem própria à Arte se circunscreve a dimensionalidade que envolve a existência humana, além de promover os complexos processos de reconhecimentos em relação ao Outro e ao mundo.

Para tanto, o jogo teatral/dramático é a pedagogia de ação que responde aos dois pólos principais do ser humano: a expressão de si mesmo e a de comunicação com o outro. Diante desse entedimento apontamento que o ensino a partir dos jogos teatrais deve ocupar um lugar específico na educação, substituindo o saber para o saber ser, Barret (2007). As atividades de natureza teatral, sobretudo os modos de jogos teatrais permitirão desenvolver competências em diferentes línguagens e impulsos de criatividades. 


\section{JOGO TEATRAL COMO PROPOSTA DE MEDIAÇÕES PERCEPTIVAS, IMAGINATIVAS DRAMÁTICAS PARA A FORMAÇÃO DO SUJEITO CRÍTICO}

O jogo teatral sob o enfoque da percepção fenomenológica de Merleau-Ponty, são considerados a partir dos campos sensoriais e no entendimento fenomenológico que se diversificam em vários aspectos. Podemos destacar que a percepção se faz por uma múltipla mediação de constructos históricos, políticos, econômicos, ideológicos, dentre outros. Tendo com base a visão de Merleau-Ponty (1999), destacamos, sobretudo, os campos psicológico e filosófico.

O referido filósofo em seu livro Fenomenologia da Percepção destaca que a "compreensão fenomenológica distingue-se da "intelecção" clássica, que se limita às "naturezas verdadeiras e imutáveis", e a fenomenologia pode tornar-se uma fenomenologia da gênese" (PONTY, 1999. p.16).

Nos estudos de Araújo (1996), essa questão sobre o plano fenomenológico de Merleau-Ponty, diretamente se relaciona com o campo das artes, requerendo o reconhecimento de que a percepção prima pela compreensão de um acontecimento histórico ou de uma doutrina, em que o processo de compreensão é dado a partir da intenção total, o que significa que o ato de perceber não é apenas aquilo.

[...] que são para a representação as "propriedades" da coisa percebida, a poeira dos "fatos históricos", as "ideias" introduzidas pela doutrina -, mas a maneira única de existir que se exprime nas propriedades da pedra, do vidro ou do pedaço de cerca, em todos os fatos históricos de uma revolução, em todos os pensamentos de um filósofo. (ARAÚJO, 1996, p.16).

Desta leitura depreendemos a inter-relação do eu, do outro e do mundo (as coisas), faz em um mundo fenomenológico, que se pode correlacionar a aplicabilidade dos jogos teatrais. A ideia é que o jogo teatral não se restrinja a uma concepção naturalizada sobre as coisas, ou melhor, uma mera prática de atuar, e de encenar por meio de personagens, alguns conceitos estáticos e estereotipados do ser humano e do seu próprio mundo. A visão fenomenológica do jogo teatral abre-se como caminho de ensinar por meio de uma percepção critica e consciente 


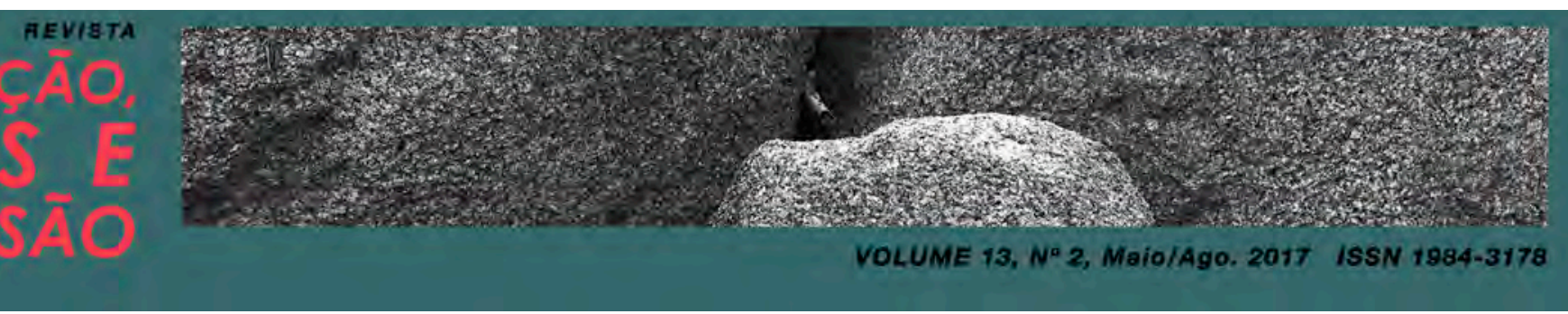

dos sentidos atribuída ao plano existencial humano e as experiências estabelecidas com o mundo exterior.

Para o uso do jogo teatral, como uma prática fenomenológica produzida no campo perceptivo de contextos sociais, pode se afirmar que o diálogo entre o ator/aluno, a história e a experiência deverá resultar em uma percepção filosófica que capture as causas e os efeitos das relações existenciais.

A fenomenologia constituída para o processo de aprendizagem, a partir do jogo teatral é diretamente vinculada ao campo das sensibilidades individuais, que são reelaboradas na esfera psicológica e posteriormente, ganham a consciência filosófica do movimento de pensar sobre as realidades representadas. Seria entender que o jogo teatral só ganha sentido quando ele promove nos seus praticantes o exercício de reflexão e ação sobre os contextos nos quais esses sujeitos estão submetidos.

Acrescenta-se que esse movimento de reflexão e ação no campo fenomenológico para Merleau-Ponty é garantido por uma percepção que parte dos princípios sensoriais e cognitivos, e que diretamente estão relacionados aos princípios de intencionalidade.

O jogo teatral interpretado a partir da visão fenomenológica de Merleau-Ponty se estabelece como uma via perceptiva da existência humana, entrelaçada no mundo das construções psíquicas afetivas ou relacionais e interligada a uma compreensão da existência desse ser no mundo.

Seria para tanto possível pensar o teatro como um processo construtivo de contextos que representam a existência humana para além de uma arena naturalizada que visa formar sujeitos/atores de forma estática inserida numa perspectiva linear dos acontecimentos históricos. Contrário a esse pensamento estático, o teatro, ou melhor, o uso do jogo teatral como instrumento educativo torna-se a essência do pensamento crítico das experiências acumuladas historicamente. O filósofo lança um desafio. Como na contemporaneidade devemos produzir conhecimentos críticos, sobre os processos sociais e ainda como reelaborar e reaprender outras formas de se ver o mundo?

Esse campo investigativo que aborda os jogos teatrais como instância formativa, ocorre o entendimento, que eles se constroem por diversos contextos vivenciados pelos 
atores/alunos no cotidiano escolar. Os jogos teatrais tornam-se possibilidades educativas, que em sua composição destacam várias etapas, a saber: perceptiva, imaginativa e criativa. Essas promovem no aluno um processo de percepção crítica sobre as realidades sociais.

Tal postulado se efetiva na compreensão de que os jogos teatrais se constituem por uma linguagem dramática em que a imaginação decorrente desse drama, gerando nos educandos e nos profissionais envolvidos no exercício da prática escolar, várias percepções e compreensões de contextos cotidianos que se manifestam como desafios para a atual sociedade brasileira.

A percepção se estabelece em um movimento direto do corpo. De que corpo falamos? Aqui, do corpo social representado pelo ator/aluno que dramatiza por meio da construção de um personagem tipo/caricatura, situações que vão para além do ato de encenar.

As experiências individuais geradas pelo campo psicológico são trazidas para o teatro e após a cena se tornam conteúdos reelaborados em uma perspectiva filosófico/crítica e reflexiva sobre o ser humano, o outro e o mundo.

A percepção se estabelece em uma relação direta do corpo e se traduz em formas de linguagens, logo essa, constitui para Merleau-Ponty também como fala daquilo que gira em torno de conexões funcionais entre os organismos e o seu meio ambiente, a partir do princípio da intencionalidade.

Para Merleau-Ponty "o âmbito do intencional ao agir motor, afetivo e sexual, o processo de constituição de sentido pode também ter lugar na espontaneidade corporal e substituir o 'eu penso' cartesiano pelo ‘eu posso' originário” (1999, p. 166). O princípio da intencionalidade se faz no entendimento do 'sentido' e do 'significado' de modo que a desejada transição de um sentido concreto e corporal para o significado linguístico não possa mais ser realizada teoricamente, mas no sentido prático-experiencial e no campo intuitivosimbólico.

\section{O JOGO TEATRAL ENTRE AS MEDIAÇÕES IMAGINATIVAS SIMBÓLICAS E OS PLANOS REAIS DA VIDA}

O jogo teatral na instância da imaginação dramática é "o jogo simbólico, é a representação corporal do imaginário”, (OLIVEIRA, 2007, p. 56). Para autora, na exploração 
da fase da imaginação, o jogador pode modificar sua vontade, usando o "faz de conta". Essa fase de 'faz de conta' é o descolamento do mundo racional lógico objetivo para a descoberta do mundo das subjetividades, das sensibilidades e das experiências reais transpostas para o plano lúdico do drama.

A imaginação dramática se expressa corporalmente, mas o desafio no plano imaginativo é promover os vínculos do drama com situações concretas reais, que são estabelecidas em cenários constituídos por relações sociais vivenciadas no e do mundo real. Para aclararmos tal entendimento se ressalta que:

a imaginação dramática, sendo parte fundamental no processo de desenvolvimento da inteligência, deve ser cultivada por todos os métodos modernos de educação. Piaget indica que o jogo está diretamente relacionado ao desenvolvimento do pensamento na criança. Com qualquer estrutura cognitiva (esquema) há dois processos associados: o jogo assimila a nova experiência e, então, prossegue pelo mero prazer do domínio; a imitação, relaciona-se com a experiência de modo a acomodá-la dentro da estrutura cognitiva - jogo para assimilar, imitação para acomodar. Embora a imitação e o jogo estejam diretamente relacionados com o processo de pensamento e com o desenvolvimento da cognição, a imaginação dramática é um fator-chave - é ela que interioriza os objetos e lhes confere significado. (KOUDELA, 1990, p.28)

Essa forma de concepção da fase imaginativa dramática reflete o próprio processo de cognição e recoloca a importância do uso do jogo teatral para aprimorar o processo de socialização. As características dos jogos simbólicos se constituem, por "liberdade de regras, desenvolvimento da imaginação e da fantasia, ausência de objetivo explícito ou consciente, lógica própria articulada com a realidade, assimilação da realidade ao 'Eu'", (OLIVEIRA, 2007, p.56) $\mathrm{Na}$ fase imaginativa dramática os processos constitutivos de personagens tipo/caricatura são os ditos mediadores do plano lúdico dramático com o plano cotidiano real.

Esses personagens refletem o nível discursivo da composição de um jogo teatral. Como relacionar o personagem na estrutura social do educando? O jogo teatral é uma forma discursiva. De que forma os cenários devem promover a reflexão/ação dentro do processo de assimilação e acomodação de realidades?

Para o entendimento do par dialético promove-se a seguinte reflexão: 
[...] tradicionalmente entende-se que somente aquilo que pode ser expresso por meio da linguagem (discurso verbal) pode ser pensado. $O$ pensamento articulado, a racionalidade, se expressa através do discurso. Langer estabelece uma diferença entre forma discursiva e a forma apresentativa. Segundo ela, onde quer que um símbolo opere, existe significado e o reconhecimento do apresentativo amplia a concepção da racionalidade para além das fronteiras tradicionais. Se aceitarmos que a função simbólica resulta de um processo espontâneo que continua o tempo todo na mente humana, o ver abstrativo é o fundamento da nossa racionalidade (KOUDELA, 1990, p.35)

Essa compreensão é essencial para o estudo do jogo teatral, primeiro como discurso, em segundo como uma forma pensada social e representada simbolicamente por textos produzidos que simbolizam cotidianos sociais diversos. A imaginação dramática é produzida por simbologias que promovem o que se entende no teatro, como processo de acomodação ${ }^{2}$ e de assimilação ${ }^{3}$ de realidades. Ainda respaldamos a presente reflexão ao contexto que,

a simbolização é pré-raciocinativa mas não pré-racional. Antes de qualquer generalização ou silogismo consciente, a mente humana elabora símbolos que refletem um esforço consciente de compreensão. Enquanto que os significados fornecidos através da forma discursiva exigem o aprendizado do vocabulário e da sintaxe, o símbolo não-discursivo prescinde de qualquer aprendizagem. As formas não-discursivos são elaboradas mais baixas do que as do discurso no sentido de que elas não exigem a intervenção do raciocínio e falam diretamente ao sentido. Enquanto que o pensamento verbal e conceitual é inicialmente exterior à criança e não pode fornecer o que foi vivido individualmente, o simbolismo lúdico, ao contrário, é elaborado pelo sujeito para seu próprio uso. (KOUDELA, 1990, p.32)

A imaginação dramática não pode ser ao algo exterior as vivências dos sujeitos/atores. O drama imaginado deverá produzir um processo de aprendizagem, pelo qual esse deverá promover mudanças nos próprios contextos sociais, nos quais o sujeito está inserido. Nesse sentido faz-se necessário pontuar as expressões discursivas que os personagens tipo/caricatura empregam nessa fase imaginativa.

\footnotetext{
2 Na Psicologia Acomodação é um conceito desenvolvido por Jean Piaget que descreve mecanismos da adaptação do indivíduo, com o objetivo de estruturar e impulsionar seu desenvolvimento cognitivo.

${ }^{3}$ Entende-se por assimilação como sendo um processo mental pelo qual se incorporam os dados das experiências aos esquemas de ação e aos esquemas existentes.
} 
De acordo com as definições dessas personagens temos as seguintes concepções. Para o personagem tipo tem-se como aquele que representa as qualidades/defeitos de uma classe social/ profissão. Quase sempre, esse entra em palco acompanhado de elementos cênicos (objetos, pessoas, animais e outros) que ajudam a caracterizá-lo, conseguindo perceber melhor os defeitos que são criticados.

Para aqueles designados como "personagens tipos" alguns contextos culturais, políticos, étnicos e outros são explorados como meio de discursos estereotipados. Esse fato evidencia a necessidade do uso do jogo para promover uma reflexão sobre as situações que envolvem essas construções dentro de um imaginário social.

Esses personagens representam sempre um grupo social. Por exemplo, tomamos os personagens que caracterizam o grupo gay. Aqui definimos como personagem tipo, aqueles que defendem os homossexuais e também defendem as coisas relacionadas ao grupo social. É necessário apontar nesse contexto que o personagem tipo para o exemplo empregado não associa aqueles que exploram situações exageradas reiterando os ditos constructos sociais que essencializam ou naturalizam o grupo em questão.

Podemos enumerar várias cenas comportamentais: vulgaridade corporal, flexão de gênero, códigos linguísticos, dentre outros. Para esses personagens gays, consideramos que os mesmos estão ali para fazer parte do livro/peça/novela e entreter o público.

Para essa fase da imaginação dramática ainda ressaltamos os "Personagens caricaturais". Existe uma abundância de características quando retratamos um personagem caricatural. Nos cenários teatrais eles refletem mazelas e desregramentos da sociedade ou de um grupo. São personagens que têm distorções propositais, a fim de ensejar o cômico, o ridículo, o satírico. O jogo teatral como uma prática educativa promove a reflexão crítica das realidades sociais do educando, as ações em que as personagens desempenham tornam-se os argumentos centrais para o processo de aprendizagem.

O jogo teatral como instrumento de ensino nas escolas pode contribuir para a constituição do imaginário social crítico, além de favorecer o desenvolvimento da sensibilidade, da visão de mundo e da imaginação dramática que postula por novas 
construções de contextos marginalizados ou excluídos do diálogo primando por rever situações de preconceito, racismo, violência dentre tantas situações problemas cotidianas.

Quando é proposto e instigado um determinado tema, sobretudo, relativo à realidade social do aluno para construção de uma cena, por meio do jogo se possibilita aos educandos se conhecimentos múltiplos dos personagens por eles criados. Esse caminho metodológico da imaginação promove na etapa de criação, situações que proporcionam ao educando, um possível encontro de inspiração para personagens presentes no cotidiano real da vida.

As histórias vividas ou contadas se tornam matéria-prima para a construção dos jogos teatrais, uma vez que, o educando poderá compor esse imaginário social, transpondo sua experiência para a cena teatral, o que seria um dos mais importantes elementos na construção cognitiva e interpretativa da construção do aluno, enquanto sujeito cênico e cidadão. De acordo com os propósitos dos PCN's Arte,

[...] o meio ambiente apresenta-se como fonte de conhecimento para a criação artística. Por intermédio das imagens, formas, cores, sons e gestualidades presentes no ambiente natural e simbólico, estabelece-se uma relação "ativo-receptiva" favorável à produção artística e recepção estética. O caráter ativo-receptivo desse encontro cria um universo particular de interação entre indivíduo/natureza e cultura, no qual pode-se estabelecer um diálogo estético e artístico, no qual as respostas também se dão por meio de ações no ambiente e na produção artística. (BRASIL, 1998, p. 39)

Tais procedimentos são primordiais para a fase de criação das cenas e da dramaturgia. Essas podem se fundar em duas práticas de exercícios simultâneos: na pesquisa por referências - do teatro, do cinema e do circo - e na realização de improvisações, por meio de jogos teatrais e ou dramáticos, em que a inspiração causada por esses jogos aplicados, poderia dar vazão à criação individual e também na colaboração de uma criação coletiva.

\section{CONSIDERAÇÕES FINAIS}

O jogo teatral é uma prática educativa. Para tanto, questionamos: como o teatro promove o desvelamento crítico das questões sociais? Como o jogo teatral pode contribuir 
para a formação do indivíduo social e produtor de conhecimentos críticos, a partir de uma prática coletiva numa perspectiva educativa? Como o jogo teatral e ou dramático pode promover à práxis consciente entre o exercício da arte e a formação escolar?

Após a leitura e a interpretação dos Parâmetros Curriculares Nacionais e dos aportes teóricos sobre Jogos teatrais, Educação e Teatro, depreendemos que esse entendimento do jogo teatral como prática educativa se faz em um processo dialético. O teatro se apresenta como arena de produção e assimilação de conteúdos, seu exercício permite no campo escolar um movimento de autoconhecimento, de conhecimento do outro e do mundo.

Nesse contexto interacional o teatro, por meio de jogos pode garantir um maior rendimento escolar. Com a prática e a concepção coletiva de se fazer teatro fica posto no estudo que essas facilitam a formação do sujeito- o educando, como ser crítico do mundo. Além de promover nele, seja como espectador ou seja como ator múltiplas percepções de uma dada realidade.

À medida que o educando produz suas percepções por meio do jogo teatral ele consegue atuar e propor soluções a determinados problemas apresentados no cotidiano social. Além disso, o uso do jogo pode aprimorar seu potencial crítico, aumentar seu envolvimento com o grupo, sua criatividade e sua ação intuitiva, situações que são essenciais para a aprendizagem, tanto no campo social quanto no contexto formal educativo.

O jogo teatral/dramático é a pedagogia de ação que responde aos dois pólos principais do ser humano: a expressão de si mesmo e a de comunicação com o outro. As atividades de natureza teatral, sobretudo, os modos de jogos teatrais permitem desenvolver competências em diferentes línguagens e impulsos de criatividades.

\section{REFERÊNCIAS}

ARAÚJO, A. R. F. de. Sobre o Olhar - A percepção fenomenológica em Merleau-Ponty. (1996), Em: http://www.eca.usp.br/nucleos/filocom/ensaio4.html. Acessado em 06/07/2013, às $06 \mathrm{~h} 14 \mathrm{~min}$. 
BRASIL. Secretaria de Educação Fundamental. Parâmetros Curriculares Nacionais: Arte. Brasília: MEC/SEC, 1998.

BRASIL. Lei de Diretrizes e Bases da Educação Nacional. Lei no 9.394, de 20 de dezembro de 1996. 3. Ed. Senado federal/Subsecretaria de Edições Técnicas, 2006.

DESGRANGES, F. Pedagogia do Teatro: provocação e dialogismo. São Paulo: Hucitec, 2006.

JAPIASSU, R.O.V. A Linguagem Teatral na Escola: Pesquisa, Docência e Prática Pedagógica. Campinas: Papirus, 2007. (Coleção Ágere)

KOUDELA, I. D. Brecht e o jogo teatral infantil. Revista Comunicações e Artes, São Paulo, v.15, n.24, p.27-34, set./dez. 1990. , p. 78.

MERLEAU-PONTY, M. Fenomenologia da Percepção. Tradução de Carlos Alberto Ribeiro de Moura. 2a . Ed. São Paulo: Martins Fontes, 1999.

OLIVEIRA, U.A.S.M. de. A criação de textos teatrais a partir dos jogos e das peças didáticas de Bertolt Brecht. 2007. 262 f. Tese (Doutorado em Educação) Faculdade de Educação, Universidade Federal da Bahia, 2007.

PAVIS, P. Dicionário de Teatro. Trad. Jacó Guinsburg e Maria Lúcia Pereira. 2. ed. São Paulo: Perspectiva, 2008.

SPOLIN, V. Jogos teatrais: o fichário de Viola Spolin. Trad. Ingrid Dormien Koudela. São Paulo: Perspectiva, 2001a. p. 56

Jogos Teatrais na Sala de Aula, Perspectiva, 2001 